OPEN ACCESS

Edited by:

Sumit Sarkar,

National Center for Toxicological Research (FDA), United States

Reviewed by:

Gyun Jee Song,

Catholic Kwandong University,

South Korea

Juliette Van Steenwinckel,

Institut National de la Santé et de la Recherche Médicale (INSERM),

France

*Correspondence: Jason L. Eriksen

jeriksen@central.uh.edu

Specialty section:

This article was submitted to

Non-Neuronal Cells,

a section of the journal

Frontiers in Cellular Neuroscience

Received: 01 September 2021 Accepted: 07 January 2022 Published: 07 February 2022

Citation: Womack TR, Vollert CT, Ohia-Nwoko O, Schmitt M, Montazari S, Beckett TL, Mayerich D, Murphy MP and Eriksen JL (2022) Prostacyclin Promotes Degenerative Pathology in a Model of Alzheimer's Disease. Front. Cell. Neurosci. 16:769347. doi: 10.3389/fncel.2022.769347

\section{Prostacyclin Promotes Degenerative Pathology in a Model of Alzheimer's Disease}

\author{
Tasha R. Womack ${ }^{1}$, Craig T. Vollert ${ }^{1}$, Odochi Ohia-Nwoko ${ }^{1}$, Monika Schmitt ${ }^{1}$, Saghi \\ Montazari ${ }^{1}$, Tina L. Beckett ${ }^{2}$, David Mayerich ${ }^{3}$, Michael Paul Murphy ${ }^{2}$ and Jason L. \\ Eriksen $^{1 *}$

\begin{abstract}
'Department of Pharmacological and Pharmaceutical Sciences, University of Houston, Houston, TX, United States, ${ }^{2}$ Department of Molecular and Cellular Biochemistry, University of Kentucky, Lexington, KY, United States, ${ }^{3}$ Department of Electrical and Computer Engineering, University of Houston, Houston, TX, United States
\end{abstract}

Alzheimer's disease (AD) is a progressive neurodegenerative disorder that is the most common form of dementia in aged populations. A substantial amount of data demonstrates that chronic neuroinflammation can accelerate neurodegenerative pathologies. In $\mathrm{AD}$, chronic neuroinflammation results in the upregulation of cyclooxygenase and increased production of prostaglandin $\mathrm{H} 2$, a precursor for many vasoactive prostanoids. While it is well-established that many prostaglandins can modulate the progression of neurodegenerative disorders, the role of prostacyclin (PGI2) in the brain is poorly understood. We have conducted studies to assess the effect of elevated prostacyclin biosynthesis in a mouse model of AD. Upregulated prostacyclin expression significantly worsened multiple measures associated with amyloid- $\beta$ (A $\beta$ ) disease pathologies. Mice overexpressing both $A \beta$ and PGI2 exhibited impaired learning and memory and increased anxiety-like behavior compared with non-transgenic and PGI2 control mice. PGI2 overexpression accelerated the development of $A \beta$ accumulation in the brain and selectively increased the production of soluble $A \beta_{42}$. PGI2 damaged the microvasculature through alterations in vascular length and branching; $A \beta$ expression exacerbated these effects. Our findings demonstrate that chronic prostacyclin expression plays a novel and unexpected role that hastens the development of the AD phenotype.

Keywords: Alzheimer's disease, prostanoid, amyloid- $\beta$, neuroinflammation, neurodegeneration

\section{INTRODUCTION}

Alzheimer's disease is an incurable neurodegenerative disorder that is the most common cause of dementia. The late-onset form of $\mathrm{AD}$ is a slowly developing, progressive disorder, with age as the most significant single risk factor. Major pathological hallmarks of the disease include the accumulation of extracellular $A \beta$ protein and intracellular tau protein, accompanied by prominent, widespread neuroinflammation (Itagaki et al., 1988; McGeer et al., 1988; Rogers et al., 1988; Eikelenboom et al., 1989). With disease progression, numerous neuroinflammatory molecules, including prostaglandins and cytokines, become dramatically upregulated within cerebrospinal fluid and throughout the brain parenchyma, and are associated 
with cognitive impairment (Casolini et al., 2002; Brüünsgaard and Pedersen, 2003; Starr et al., 2009; Cribbs et al., 2012). These findings suggest that persistent inflammation may be a driver of neurodegenerative disease (Holmes et al., 2009; Noble et al., 2010; Simen et al., 2011). The prostanoid family of lipid metabolites are the main mediators of acute inflammatory responses; however, their role in chronic inflammatory disease states remains controversial due to the dual role of many prostanoid receptors (Ricciotti and FitzGerald, 2011). For example, prostaglandin $\mathrm{D} 2\left(\mathrm{PGD}_{2}\right)$ bound to the PGD receptor (DP) stimulates mast cell secretion of type 2 cytokines in the lung leading to eosinophil infiltration and bronchoconstriction, clinically known as allergic asthma (Matsuoka et al., 2000). Conversely, in the CNS, DP1 receptor activation attenuated glutamate toxicity in organotypic hippocampal cultures indicating a neuroprotective role of prostanoid receptors (Liang et al., 2005b).

Prostanoids represent a broad class of arachidonic-acidderived molecules, including thromboxane, prostaglandins, and prostacyclin, that can exhibit paracrine signaling activity. Prostanoid biosynthesis is carried out by cyclooxygenase (COX) enzymes. Typically, these prostanoids fill a variety of diverse physiological processes that are important for tissue homeostasis (Edelman et al., 2013; Liu et al., 2013; Vitale et al., 2013). Inflammatory events and neurotoxic insults can significantly upregulate prostanoid expression, a process that significantly contributes to the $\mathrm{AD}$-associated neuroinflammatory response (Yermakova et al., 1999; Hoozemans et al., 2001; Choi and Bosetti, 2009; Coma et al., 2010). In Alzheimer's disease, one of the crucial triggers associated with prostanoid up-regulation is the accumulation of $A \beta$ protein, which both stimulates pro-inflammatory cytokine production and increases cellular phospholipase activity, the first step in prostanoid biosynthesis (Desbène et al., 2012; Shi et al., 2012; Sagy-Bross et al., 2013).

The liberation of fatty acid substrates, such as arachidonic acid, is the initiating step of the prostanoid signaling cascade. Free arachidonic acid undergoes conversion, in a two-step reaction, to prostaglandin $\mathrm{H} 2$ (PGH2) by COX enzymes. Two major COX enzymes exist, COX-1 and COX-2, which have distinct but overlapping tissue profiles and activities. COX-1 is expressed in the periphery and is a consistently active enzyme that is important for the maintenance of tissue homeostasis. In contrast, COX-2 represents an inducible form of the enzyme. In the brain, COX-2 expression usually is low but becomes dramatically upregulated in Alzheimer's disease (Kitamura et al., 1999; Hoozemans et al., 2008). Prostaglandin E2 ( $\left.\mathrm{PGE}_{2}\right)$, prostaglandin $\mathrm{D} 2\left(\mathrm{PGD}_{2}\right)$, prostacyclin $\left(\mathrm{PGI}_{2}\right)$, prostaglandin $\mathrm{F} 2 \alpha\left(\mathrm{PGF}_{2 \alpha}\right)$, and thromboxane $\mathrm{A} 2\left(\mathrm{TXA}_{2}\right)$ become upregulated with COX-2 expression; several of these prostanoids, such as $\mathrm{PGE}_{2}$ and $\mathrm{PGD}_{2}$, can stimulate $\mathrm{A} \beta$ production and can play roles in other amyloid associated pathologies (Liang et al., 2005a; Hoshino et al., 2009; Keene et al., 2010; Zhen et al., 2012). However, the impact of increased $\mathrm{PGI}_{2}$ in $\mathrm{AD}$ is not well understood.

Prostacyclin is synthesized from arachidonic acid through a two-step reaction of the COX and $\mathrm{PGI}_{2}$ synthase (PGIS) enzymes. $\mathrm{PGI}_{2}$ acts via the G-protein coupled IP receptor to activate adenylyl cyclase and protein kinase A, thereby increasing intracellular cAMP to produce vasodilatory and anti-inflammatory effects (Cheng et al., 2002). While prostacyclin signaling is largely associated with peripheral vasoregulatory activity, multiple cell types in the brain express both PGIS and the IP receptor, including neurons, glia, endothelial cells, and smooth muscle cells (Oida et al., 1995; Siegle et al., 2000; Fang et al., 2006). These findings suggest that prostacyclin may act as a modulator of CNS activity.

Experimental applications of stable analogs of $\mathrm{PGI}_{2}$ within the brain have shown improvements in vascular functions and recovery from neuronal damage. For example, the application of iloprost, a stable analog of $\mathrm{PGI}_{2}$, was able to significantly reduce infarct size after $6 \mathrm{~h}$ of middle cerebral artery occlusion in rabbits (Dogan et al., 1996). While the infusion of TEI7165 , another analog of $\mathrm{PGI}_{2}$, was able to rescue hippocampal neurons and improve response latencies in a step-down passive avoidance test in gerbils subjected to forebrain ischemia (Matsuda et al., 1997). Additionally, $\mathrm{PGI}_{2}$ appears to impact influence behavior and cognitive processing positively; $\mathrm{CP}-\mathrm{Tg}$ mice contain a modified Cyclooxygenase-1 enzyme-linked to Prostacyclin-I synthase, which elevates levels of $\mathrm{PGI}_{2}$ production (Ruan et al., 2006, 2008; Ling et al., 2018) by 60\% in the CNS (Vollert et al., 2014). In our previous work, we found that increased levels of $\mathrm{PGI}_{2}$ improved short-term memory as the $\mathrm{CP}-\mathrm{Tg}$ mice learned significantly faster in training compared to controls in a contextual fear conditioning test (Vollert et al., 2014).

Several studies have suggested that $\mathrm{PGI}_{2}$ may have some impact on neurodegenerative disorders such as Alzheimer's disease (Bush et al., 1990; Smith et al., 2004). He et al. (2017) was able to show that agonist-induced activation of the IP receptor stimulated production of soluble amyloid precursor protein $\alpha(\operatorname{sA} \beta P P \alpha)$, a neuroprotective isoform of the $A \beta$ precursor protein $(\mathrm{A} \beta \mathrm{PP})$, in isolated human microvascular endothelial cells. Wang et al. (2016) demonstrated that injections of $\mathrm{PGI}_{2}$ into an $\mathrm{A} \beta \mathrm{PP} /$ presenilin 1 transgenic mouse model increased $\mathrm{A} \beta$ levels and proposed this was due to upregulation of the anterior pharynx defective 1 homolog $\alpha(\mathrm{APH}-1 \alpha)$ subunit of the A $\beta P P$ cleaving protein, $\gamma$-secretase, via the PKA/CREB and JNK/cJun pathways. $\gamma$-secretases are responsible for cleavage of the $\mathrm{A} \beta \mathrm{PP}$ to produce cytotoxic $\mathrm{A} \beta$ peptides, suggesting that $\mathrm{PGI}_{2}$ may regulate $A \beta$-associated pathology. These data suggest that increased $\mathrm{PGI}_{2}$ is likely to play a modulatory role in cognitive function associated with A $\beta$ PP metabolism.

For this work, we evaluated the effect of $\mathrm{PGI}_{2}$-overexpression in a model of neurodegenerative disease. CP-Tg mice were crossed to APdE9 mice, a model of Alzheimer's disease that develops prominent $A \beta$ pathology and develops spatial memory impairments by 12 months of age (Lalonde et al., 2005). APdE9/CP-Tg mice, along with age-matched controls, were subjected to behavioral tests to assess possible changes in cognitive and anxiety-like behaviors. To investigate the impact of prostacyclin overexpression on the $\mathrm{A} \beta$ phenotype, we performed $\mathrm{A} \beta$ ELISAs on whole brain homogenates. We also investigated prostacyclin-mediated changes to the neurovasculature using immunohistochemical imaging. 


\section{MATERIALS AND METHODS}

\section{Animal Model}

All experiments were conducted following approved IACUC guidelines, using approved protocols, and mice were housed at the University of Houston Animal Care Facility. Mice were kept in group cages and exposed to a 12-h light/12-h dark cycle. To develop the APdE9/CP-Tg mouse model, CP-Tg mice, that express a hybrid enzyme complex linking COX-1 to PGIS by an amino acid linker of 10 residues (COX-1-10aa-PGIS; Ruan et al., 2006, 2008; Ling et al., 2018), were crossed to APdE9 mice, a bigenic model expressing the human APP Swedish mutation and the exon-9-deleted variant of presenilin-1 (dE9; Holcomb et al., 1998, 1999). PCR analysis was used to confirm the genotype. Heterozygous mice were used for all studies. Studies composed of a balanced mixture of male and female mice.

\section{Open Field Activity}

The open-field test was used to analyze exploratory behavior within a $60 \mathrm{~cm} \times 40 \mathrm{~cm}$ open chamber in normal lighting conditions. Each animal was placed in the center of the apparatus and was given $30 \mathrm{~min}$ to freely explore the arena. The movement was monitored by a computer-operated system (Optomax, Columbus Instruments, $\mathrm{OH}$ ) that recorded the time each mouse spent moving, resting, or along the margin of the arena.

\section{Light Dark Exploration}

As a measure of anxiety-like behavior, a single mouse is placed in an apparatus consisting of a light and dark compartment separated by a single opening and their movements are recorded (Vollert et al., 2014). Mice were subjected to light-dark exploration test to evaluate anxiety-like behavior at three and 6 months of age. The light-dark box consisted of a light compartment $(27 \mathrm{~cm} \times 27 \mathrm{~cm} \times 27 \mathrm{~cm})$ and a dark compartment $(27 \mathrm{~cm} \times 18 \mathrm{~cm} \times 27 \mathrm{~cm})$ separated by a partition with a single opening $(7 \mathrm{~cm} \times 7 \mathrm{~cm})$ to allow passage between compartments as previously described More time spent in the dark compartment and fewer transitions is considered anxiogenic. Each trial lasted $5 \mathrm{~min}$. The number of transitions were measured manually, with the observer blinded to the genotype.

\section{Elevated Plus-Maze}

Anxiety-like behavior can be assessed by utilizing an elevated-plus maze where the mouse has the option to explore two open freely and lit arms, or two arms closed in with blinders. The plus-shaped apparatus is $40 \mathrm{~cm}$ above the ground, and mouse movements were recorded by an overhead camera. Time in the light and number of transitions between arms were manually recorded with the observer blinded to the genotype.

\section{Rotarod}

An accelerating cylindrical drum Rotamex Rotarod machine (Columbus Instruments, Columbus, $\mathrm{OH}$ ) was used to evaluate motor learning and coordination in 12-month-old animals. The rotarod consists of horizontal accelerating rods (4-40 rpm) and plastic partitions between each mouse. The mouse is then subjected to four trials a day for 2 days with 15-min intervals between each trial. A trial ended when the mouse fell off the rod, the time elapsed $300 \mathrm{~s}$, or the mouse became inverted twice in the same trial without falling.

\section{Fear Conditioning}

Testing for contextualized and cued fear conditioning was followed as previously described in mice at 6 months of age (Martinez et al., 2007; Elhardt et al., 2010). A standard fear conditioning chamber $(13 \times 10.5 \times 13 \mathrm{~cm}$, Med Associates $)$ with 19 metal rods equally spaced on the floor was used to condition the mice. Training consisted of a 7-min session where a single mouse was subjected to a foot shock (2-s, $0.75 \mathrm{~mA}$ ) paired with an auditory tone at 120,240 , and 360 s. To test for conditioning to contextual cues, the mouse was returned to the chamber $1 \mathrm{~h}$ and $24 \mathrm{~h}$ after the training session. The contextual tests were also 7-min sessions. However, the shock was not presented. For the 24-h cue test, mice were returned to the chamber after the surroundings and smell had been altered and during the 7-min session, a 3 -min tone was presented from minute 3 to 6 . Freezing behavior was measured using computer software (FreezeFrame, Med Associates/Actimetrics).

\section{A $\beta$ ELISA}

Mice were sacrificed after behavioral testing, and brains were collected. Briefly, hemibrains were homogenized in $1 \times$ PBS buffer ( $\mathrm{pH}=7.4,1.0 \mathrm{ml} / 150 \mathrm{mg}$ of tissue) using a PowerMax AHS 200 homogenizer and centrifuged at $14,000 \times g$ for $30 \mathrm{~min}$ at $4^{\circ} \mathrm{C}$. The supernatant was collected, and the pellet re-extracted in RIPA buffer (50 mM Tris- $\mathrm{HCl}, 150 \mathrm{mM} \mathrm{NaCl}, 1 \%$ Triton X$100,0.5 \%$ Deoxycholate, $0.1 \%$ SDS, $1 \times$ PIC, $\mathrm{pH}=8.0$ ) and the supernatant collected again. Sandwich ELISAs were performed for monomeric $A \beta 42$ using the antibodies 2.1.3 (A $\beta 42$ end specific, to capture) and Ab9 (human sequence $A \beta 1-16$, to detect). Standards and samples were added to plates after coating the wells with 2.1.3 antibody in PBS and blocking with Synblock (Pierce). Detection antibodies were then applied and developed with TMB reagent (Kirkegaard and Perry Laboratories). The reaction was stopped using 6\%o-phosphoric acid and read at $450 \mathrm{~nm}$ in a BioTek plate reader.

\section{Quantification of A $\beta$ Pathology}

4G8 antibody (1:500 dilution; Covance, cat no. SIG-39220) was used to detect $A \beta$ pathology in $10 \mu \mathrm{m}$ thick coronal brain slices. Slices were blocked for endogenous peroxidase using 3\% hydrogen peroxide and blocked using 5\% serum. Primary antibody was applied and incubated overnight at $4^{\circ} \mathrm{C}$ followed by a biotinylated secondary goat anti-mouse antibody (Jackson Immunoresearch) incubation for $20 \mathrm{~min}$ at room temperature and incubation with a Streptavidin/HRP label (Jackson Immunoresearch), followed by visualization with DAB.

Plaque expression in the entire cortex was quantified for each subject. Briefly, five brain sections, equally spaced through the cortex, from each subject were digitally captured and montaged at $10 \times$ using an Olympus DSU system using Neurolucia (Microbrightfield). The entire cortex was outlined, and Image $J$ particle analysis with thresholding was used to quantify total $A \beta$ burden, number, and average size for five 
sections. Studies were performed blinded for the genotype of each subject.

\section{Immunofluorescence Staining}

The primary antibodies used were Collagen IV (1:400 dilution; Cosmo Bio, Catalog Number LSL-LB1403) and CD13 (1:100 dilution; R\&D Systems, Catalog Number AF2335), NeuN (1:200 dilution; Millipore Sigma, Catalog Number MAB377 Clone A60), Iba 1 (1:200 dilution; FUJIFILM Wako Chemicals, Catalog Number 019-19741). Mice were sacrificed by decapitation, and brains were dissected. Brains were postfixed by immersion in Accustain (Sigma Aldrich). After fixation, brains were cryoprotected in 30\% sucrose and cut into $60 \mu \mathrm{m}$ thick sections with a cryostat. Free-floating coronal brain slices were subjected to a protein block at room temperature for $30 \mathrm{~min}$. Slices were then incubated with primary antibodies at their respective concentrations overnight at $4^{\circ} \mathrm{C}$, followed by consecutive incubations of biotinylated anti-rabbit secondary antibody (1:200; Jackson Immunoresearch) and biotinylated anti-goat secondary antibody (1:200; Jackson Immunoresearch) both for $1 \mathrm{~h}$ at room temperature. DyLight fluorophores (Jackson Immunoresearch) were added after each secondary incubation. Slices were then mounted onto glass slides under coverslips using Fluoro-Gel II mounting media with DAPI (Electron Microscopy Services).

\section{Confocal Microscopy Analysis}

Quantification of vessel parameters and pericyte coverage was performed on $60 \mu \mathrm{m}$ microtome brain slices. Five slices evenly spaced between plates 40 and 65 of the Franklin and Paxinos Mouse Brain Atlas (Franklin and Paxinos, 2019) were selected from each of five mice in each genotype for immunofluorescence staining. Blood vessels were visualized by collagen IV and pericytes by CD13 immunostaining. Three randomly selected areas of the cortex from each of the five slices were used for analysis. Z-stacks of $60 \mu \mathrm{m}$ thickness were captured using a Confocal LS microscope (THOR Labs). Neurons were visualized by NeuN staining and three randomly selected areas of the cortex from each of three slices were used for analysis. Hyperactivated microglia were visualized by Iba 1 staining. Whole coronal brain slices were imaged and the entire cortex of three slices was used for analysis. NeuN and Iba 1 staining were captured at $20 \times$ as two-dimensional images using a Confocal LS microscope (Leica). Quantification of vessel parameters was performed using a blood vessel and network analysis plugin, Tube Analyst, in ImageJ (Tosi and Tischer, 2016). Pericyte coverage analysis was performed using the ImageJ JACoP plugin as previously described (Dunn et al., 2011). All $z$-stacks were processed with background subtraction and analyzed using automatic thresholding. Quantification of neuronal cell numbers was performed using ImageJ's analyze particles feature after images were processed with background subtraction and a watershed mask. Hyperactivated microglia within the cortex were counted manually after blinding and randomization of the images. Iba 1 -positive cells were only marked counted if a DAPI-positive nucleus was present.

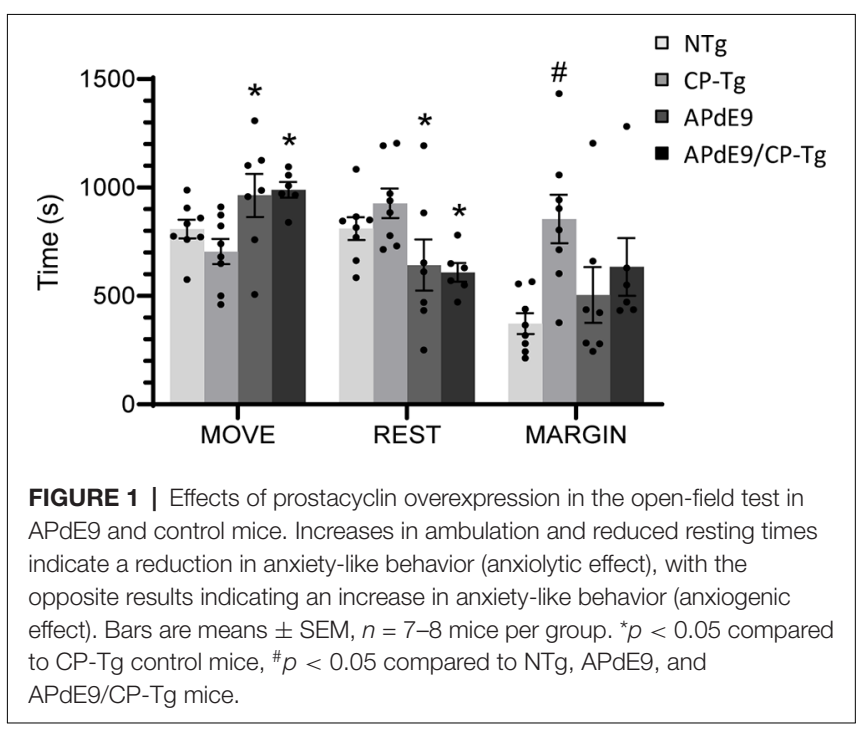

\section{Statistical Analysis}

Results for the contextualized and cued fear conditioning assays were analyzed using a repeated measures ANOVA; we analyzed all other data using factorial ANOVA followed by Fisher LSD post hoc comparisons using Statistica (Tibco Software). A $p$ value less than 0.05 was considered significant. All values are represented as S.E.M.

\section{RESULTS}

\section{Impacts on Locomotor Activity and Anxiety-Like Behavior}

Analysis of open field data, a test for locomotor activity and anxiety-like behavior, revealed that ambulation, resting, and margin times differed among the mouse lines. CP-Tg mice exhibited significant anxiety-like behavior measured by greater times spent resting and in the margin with less time spent moving (Figure 1, $p<0.05$ ). APdE9 lines showed significant increases in ambulation and reductions in resting times, indicating an anxiolytic-like effect when compared to the CP-Tg or non-transgenic (NTg) controls (Figure 1, $p<0.05$ ). Prostacyclin overexpression in the APdE9/CP-Tg mice did not affect $\mathrm{A} \beta$-mediated anxiety-like behavior as no differences were observed between the APdE9 mice and APdE9/CP-Tg mice (Figure 1).

The light-dark exploration test and the elevated plus-maze were used to evaluate anxiety. In the light-dark exploration test, a decrease in exploratory behavior in the lighted area and a preference for the dark compartment was considered a measure of anxiety-like behavior. We found that prostacyclin overexpressing mice spent significantly less time in the light compartment than the NTg control mice (Figure 2A, $p<0.05$ ). Anxiety-like behavior was also measured using an elevated plusmaze, with increased time in the lit open-arm of the plus-maze associated with anxiolytic behavior. Both the $A \beta$ and prostacyclin expressing mice spent significantly less time in the open arms and made fewer transitions, indicative of anxiogenic behavior, 

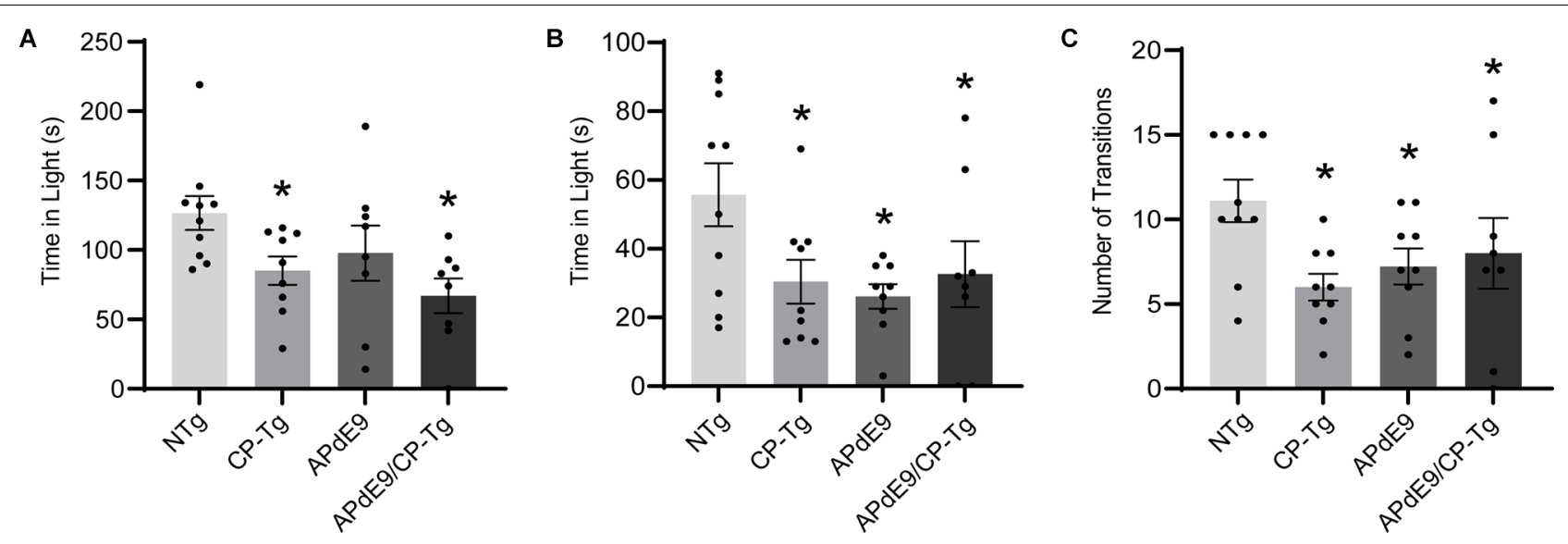

FIGURE 2 | Prostacyclin overexpression increased anxiety-like behavior as measured by light-dark and elevated plus-maze tests. (A) CP-Tg and APdE9/CP-Tg mice spent significantly less time in the light during light-dark exploration. (B) In the elevated plus-maze, all transgenic mouse lines spent significantly less time in the lit arms and made fewer transitions between the open and closed arms (C) of the elevated plus-maze. Bars are means \pm SEM, $n=8-10$ mice per group.

${ }^{*} p<0.05$ compared to NTg mice.

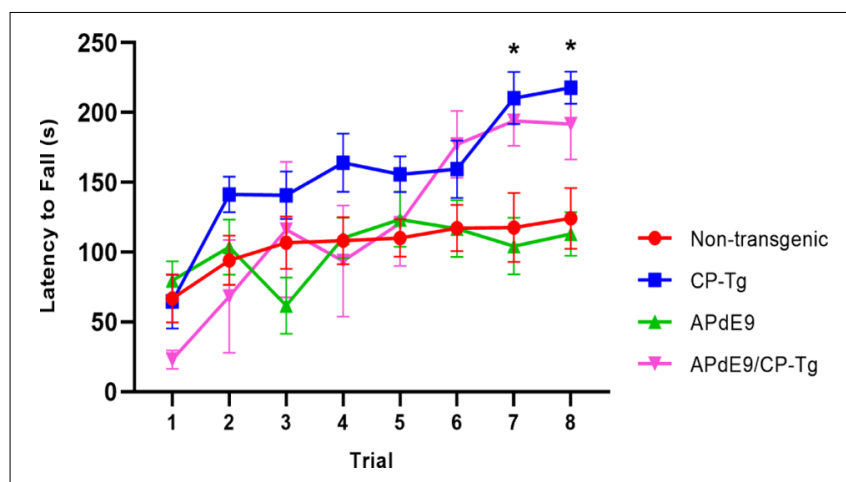

FIGURE 3 | Prostacyclin overexpression enhances motor learning and coordination. In 14-17-month-old mice, both CP-Tg and APdE9/CP-Tg mice showed improved coordination on the rotarod, compared with NTg and APdE9 mice on trials 7 and 8. Bars are means \pm SEM, $n=7-8$ mice per group. ${ }^{*} p<0.05$ compared to NTg and APdE9 mice.

compared to the non-transgenic control group (Figures 2B,C, $p<0.05)$.

\section{PGIS Overexpression Improves Motor Coordination}

Motor function and coordination were assessed using a motorized rotarod. $\mathrm{CP}-\mathrm{Tg}$ and APdE9/CP-Tg mice had an increased latency to fall in trials 7 and 8 indicating PGIS overexpression increases coordination and balance in mice 14-17 months of age (Figure 3, $p<0.05$ ).

\section{PGIS Overexpression Impairs Associative Learning}

Context/cue fear conditioning tests were run to assess prostacyclin-mediated changes in associative learning of $\mathrm{AD}$ mice measured by percent freezing. During training, mice were conditioned with three shocks paired with a tone. The
APdE9/CP-Tg mice displayed delayed learning to the aversive shocks when compared to the APdE9 mice as well as the CP-Tg and NTg controls as the magnitude of the freezing response was decreased in the training period (Figure 4A, $p<0.05$ ). $\mathrm{CP}-\mathrm{Tg}$ mice also demonstrated delayed learning compared to the APdE9, and NTg controls after the first and second shock but had an increased fear response from that of the APdE9/CP-Tg mice for the 3rd shock in the last 2 min (Figure 4A, $p<0.05$ ). APdE9 mice maintained comparable learning to that of the NTg control mice with no differences seen in percentage freezing during the entire training trial (Figure 4A).

A contextual fear conditioning trial was performed $1 \mathrm{~h}$ after training. In the same environment but with no tone presented, APdE9/CP-Tg freezing responses were significantly reduced compared to that of NTg (Figure 4B, $p<0.05$ ). The APdE9 mice showed a significant enhancement in freezing response during minutes 5 and 6 compared to the control (NTg and CP-Tg) mice (Figure 4B, $p<0.005$ ).

To assess long-term memory consolidation, another contextual trial was performed $24 \mathrm{~h}$ after training. The APdE9 mice maintained a high percentage of freezing times like the results seen in the 1 -h context trial (Figure $4 \mathrm{C}, p<0.05$ ). Percentage freezing times for the APdE9 mice were not significantly different from the NTg and CP-Tg controls. During a 24 -h cued conditioning trial where a 3 -min tone is presented in a different environment, all mice exhibited an increased freezing response to the tone with no significant differences by the end of the 7-min trial period. However, CP-Tg and APdE9/CP-Tg mice did exhibit significantly more activity measured by lower percentage freezing, compared with NTg and APdE9 mice, before the tone was presented (Figure 4D, $p<0.05$ ).

\section{Prostacyclin Drives A $\beta$ Production and Increases Amyloid Burden}

An enzyme-linked immunosorbent assay of $A \beta 40$ and $A \beta 42$ was used to determine the impact of elevated $\mathrm{PGI}_{2}$ synthesis on $\mathrm{A} \beta$ 
A

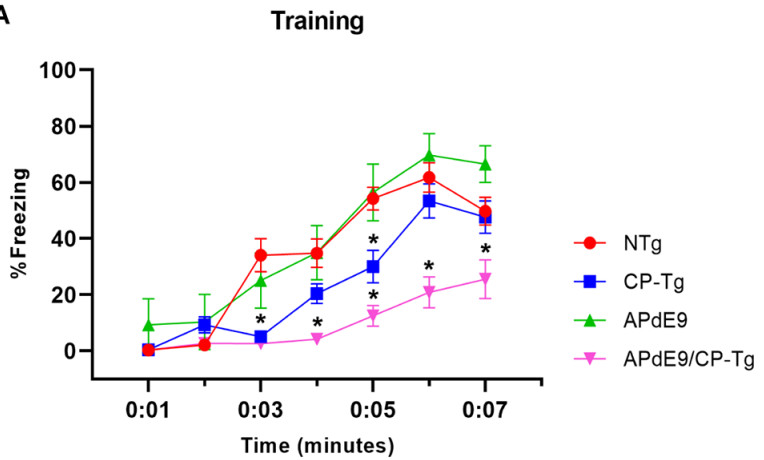

C

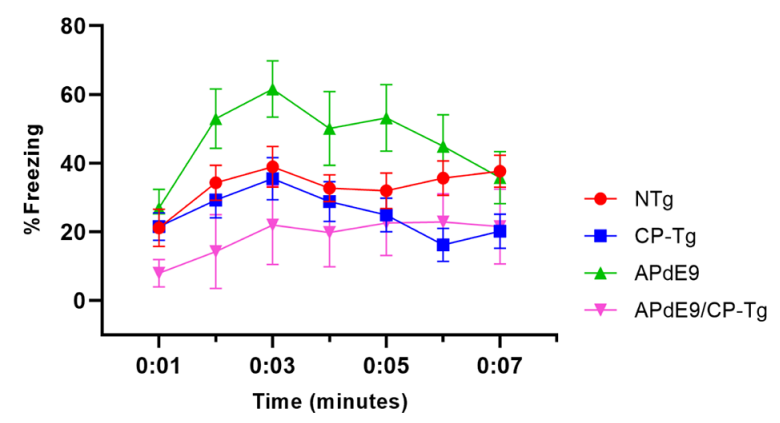

B

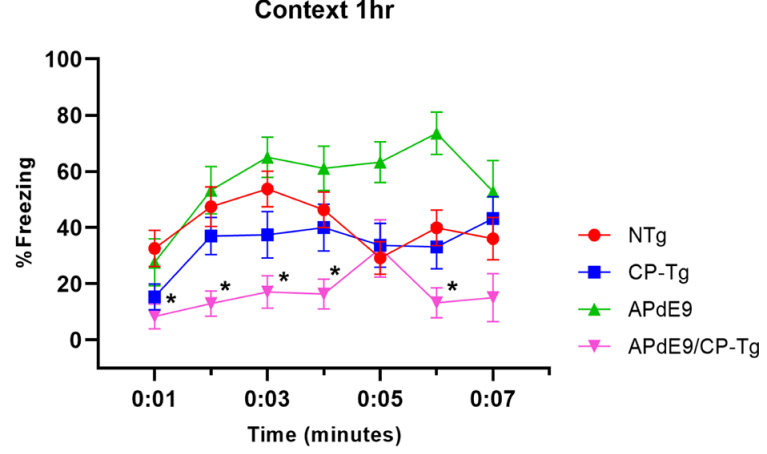

D

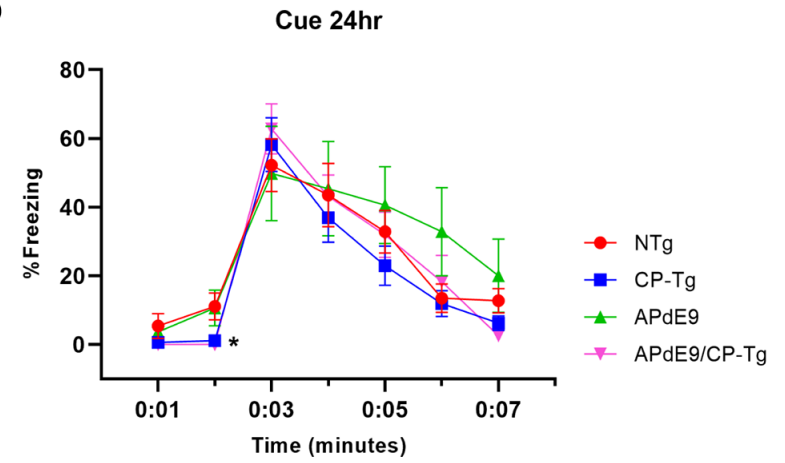

FIGURE 4 | APdE9/CP-Tg mice exhibit impaired learning. (A) PGIS overexpression significantly decreased the percentage freezing time after the first and second shock (shock given at 2 nd and 4 th $\mathrm{min}$ ) of the training trial $(p<0.05)$ while the combination of $A \beta$ and prostacyclin further decreased freezing times during training. (B) APdE9 mice exhibited an enhanced short-term memory response while APdE9/CP-Tg mice exhibited a depressed short-term memory response. (C) CP-Tg and APdE9/CP-Tg mice exhibited worse performance in a contextual test of long-term memory compared to APdE9 mice. (D) CP-Tg and APdE9/CP-Tg mice showed an initial delay in freezing at the 2nd min; however, no significant differences were observed after application of the 3-min tone from minute 3 to 6 in a cued assessment of long-term memory. $N=7-14$ mice per group. ${ }^{*} p<0.05$ compared to NTg mice. PGIS, PGI2 synthase.

production in the APdE9 mouse model. At 17-21 months of age, the APdE9 and APdE9/CP-Tg mice showed significant increases in both PBS-soluble levels of $\mathrm{A} \beta 40$ and - 42 compared to the $\mathrm{NTg}$ or CP-Tg controls (Figure $5 \mathrm{~A}, p<0.05$ ). When comparing the APdE9/CP-Tg mice to the APdE9 controls, the double transgenic line exhibited comparable levels of soluble $\mathrm{A} \beta 40$ and had a selective increase in soluble $\mathrm{A} \beta 42$ (Figure $5 \mathbf{A}, p<0.05$ ). Levels of insoluble $A \beta 40$ and -42 in the brain were measured using a RIPA extraction. Again, the APdE9 and APdE9/CP-Tg mice had increased levels of both $A \beta 40$ and -42 compared to the NTg or CP-Tg controls (Figure 5B, $p<0.0005$ ), with the double transgenic line having an approximately 1.7-fold and 1.5-fold increases in insoluble $\mathrm{A} \beta 40$ and -42 , respectively, compared to the APdE9 mice.

Increased production was reflected in higher $A \beta$ burdens. Compared to the APdE9 mice, the APdE9/CP-Tg mice contained a significantly increased burden. The average plaque diameter in the APdE9/CP-Tg mice was significantly larger, with a mean $40 \%$ increase in plaque volume compared to APdE9 mice (Figure 6, $p<0.05$ ). Although existing plaques were significantly larger, a notable finding from this study was that there was no significant difference in the number of plaques between different genetic lines.

\section{Loss of Pericyte Coverage in Prostacyclin-Overexpressing Lines}

A colocalization study was performed to assess the effect of prostacyclin overexpression on pericyte death in an $\mathrm{AD}$ mouse model. The colocalization of CD-13-positive pericytes with collagen IV-positive microvessels was expressed as Manders Colocalization Coefficients (MCC; M1: the fraction of CD-13 overlapping collagen IV, M2: the fraction of collagen IV overlapping CD-13; Dunn et al., 2011). In NTg mice, approximately $79 \%$ of $\mathrm{CD}-13$ positive pericytes co-located with collagen IV-positive basement membrane, but in CP-Tg mice, this was significantly decreased $\left(F_{(3,95)}=13.41, p<0.05\right)$ to nearly $73 \%$ (Table 1). Both $A \beta$-expressing models exhibited further reductions in pericyte coverage; APdE9 mice had 65\% coverage, and APdE9/CP-Tg had 62\% (Table 1, $p<0.05$ ). Representative images of each genotype are presented in Figure 7.

\section{APdE9/CP-Tg Mice Exhibit Severe Vascular Pathology}

To examine prostacyclin-mediated structural changes to the cerebral vasculature, we examined stains of the vessel basement 


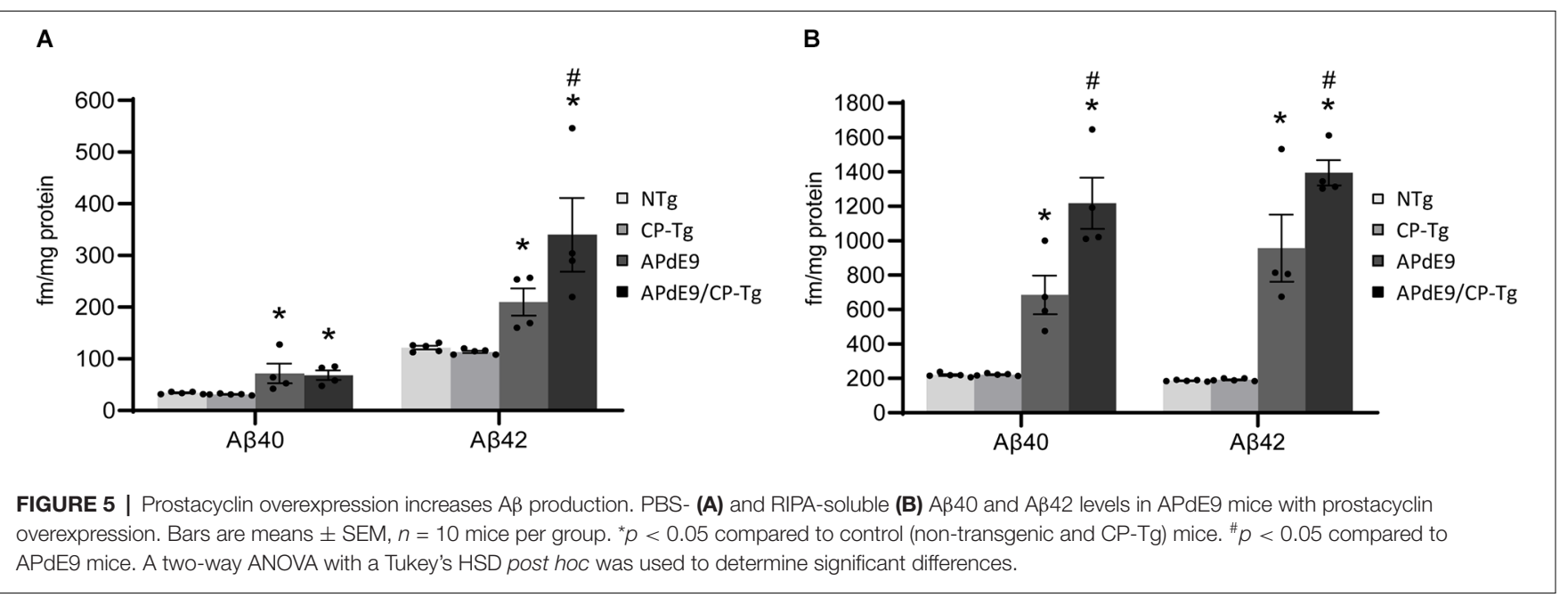

A

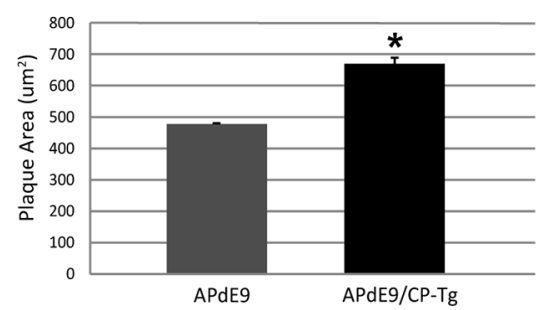

B

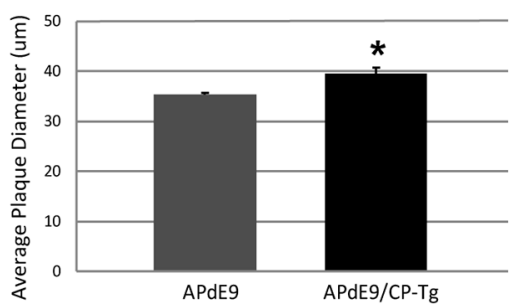

C

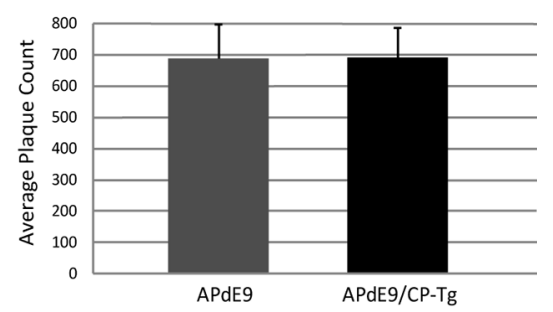

FIGURE 6 | Prostacyclin overexpression increases plaque area and diameter in the brains of APdE9 mice. Measurements in five sections of the whole cortex determined (A) average plaque area, (B) average plaque diameter, and (C) cumulative plaque count per subject. Bars are means \pm SEM, $n=10$ mice per group. ${ }^{*} p<0.05$ compared to APdE9 control mice. A one-way ANOVA was used to determine significant differences.

TABLE 1 | Effect of PGIS overexpression on colocalization of microvessels and pericytes.

\begin{tabular}{|c|c|c|c|c|c|c|}
\hline & \multicolumn{2}{|c|}{ MCC M1 } & \multicolumn{2}{|c|}{ MCC M2 } & \multicolumn{2}{|c|}{$\begin{array}{l}\text { Pearson's } \\
\text { coefficient }\end{array}$} \\
\hline & Mean & SEM & Mean & SEM & Mean & SEM \\
\hline NTg & 0.808 & 0.012 & 0.788 & 0.020 & 0.859 & 0.013 \\
\hline CP-Tg & 0.796 & 0.016 & ${ }^{\#} 0.728$ & 0.022 & 0.774 & 0.019 \\
\hline APdE9 & ${ }^{\star} 0.852$ & 0.011 & ${ }^{*} 0.652$ & 0.018 & 0.783 & 0.008 \\
\hline APdE9/CP-Tg & 0.788 & 0.011 & ${ }^{*} 0.624$ & 0.023 & 0.704 & 0.016 \\
\hline
\end{tabular}

Pearson's and Manders Colocalization Coefficients (MCC) from dual immunofluorescent stains of collagen $N$ within the basement membrane of microvessels and $C D-13$ positive pericytes. M1 signifies the fraction of immunodetectable CD-13-positive pericytes overlapping Collagen IV-positive microvessels. M2 signifies the fraction of immunodetectable collagen IV-positive basement membrane overlapping CD-13-positive pericytes. ${ }^{*} p<0.05$ compared to NTg and CP-Tg mice. ${ }^{*} p<0.05$ compared to NTg mice.

membrane using confocal microscopy. Three-dimensional image stacks were analyzed using a vessel tracing software plugin in ImageJ. Vascular parameters, including total vessel length, branch number and length, vessel cross-section and diameter, and fractional vessel volume were quantified in the cortex of 17-20-month-old NTg, CP-Tg, APdE9, and APdE9/CP-Tg mice (Figure 8A). The vascular parameters are reported as a percent of the total vessel volume imaged. APdE9/CP-Tg mice had significantly shorter and fewer vessels compared to the other models (Figures 8B-D, $p<0.05$ ). CP-Tg mice were found to have a significant increase in both total vessel length and the number of branches compared to NTg mice (Figures 8B,C, $p<0.05)$. APdE9/CP-Tg mice also presented with the smallest vessel cross-sections and diameters, APdE9 mice with the second smallest, and then CP-Tg mice when compared to NTg mice (Figures 8E,F, $p<0.05$ ). The imaged volume fraction occupied by vessels was largest for NTg mice and smallest for APdE9/CPTg mice (Figure 8G, $p<0.05$ ).

\section{Degenerative Pathology Associated With Prostacyclin Overexpression Is Not due to Cortical Neuronal Loss}

Possible changes in the neuronal loss were assessed using neuronal cell staining and confocal microscopy. Two-dimensional images of cortical neurons were collected, and cell bodies were counted using the particle analyzer plugin in ImageJ. Cell counts are reported as the number of cells detectable in a $20 \times$ field of view (Figure 9A). No changes in neuronal 


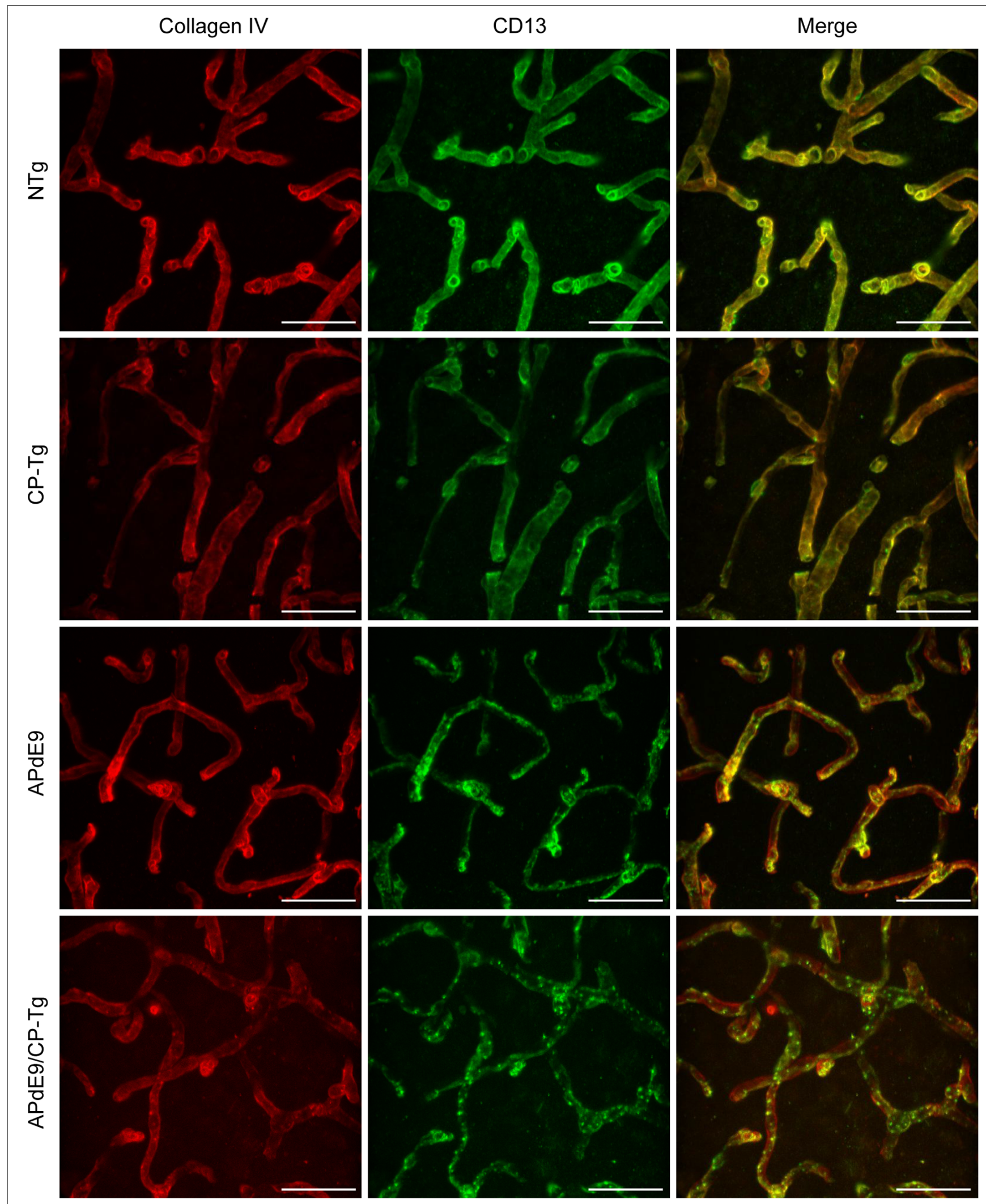

FIGURE 7 | Loss of continuous pericyte coverage in APdE9/CP-Tg mice. 100× confocal image stacks of collagen IV-positive microvessels and CD13-positive pericytes from the cortex of 17 to 20-month-old NTg, CP-Tg, APdE9, and APdE9/CP-Tg mice. Scale bar $=30 \mu \mathrm{m}$. 


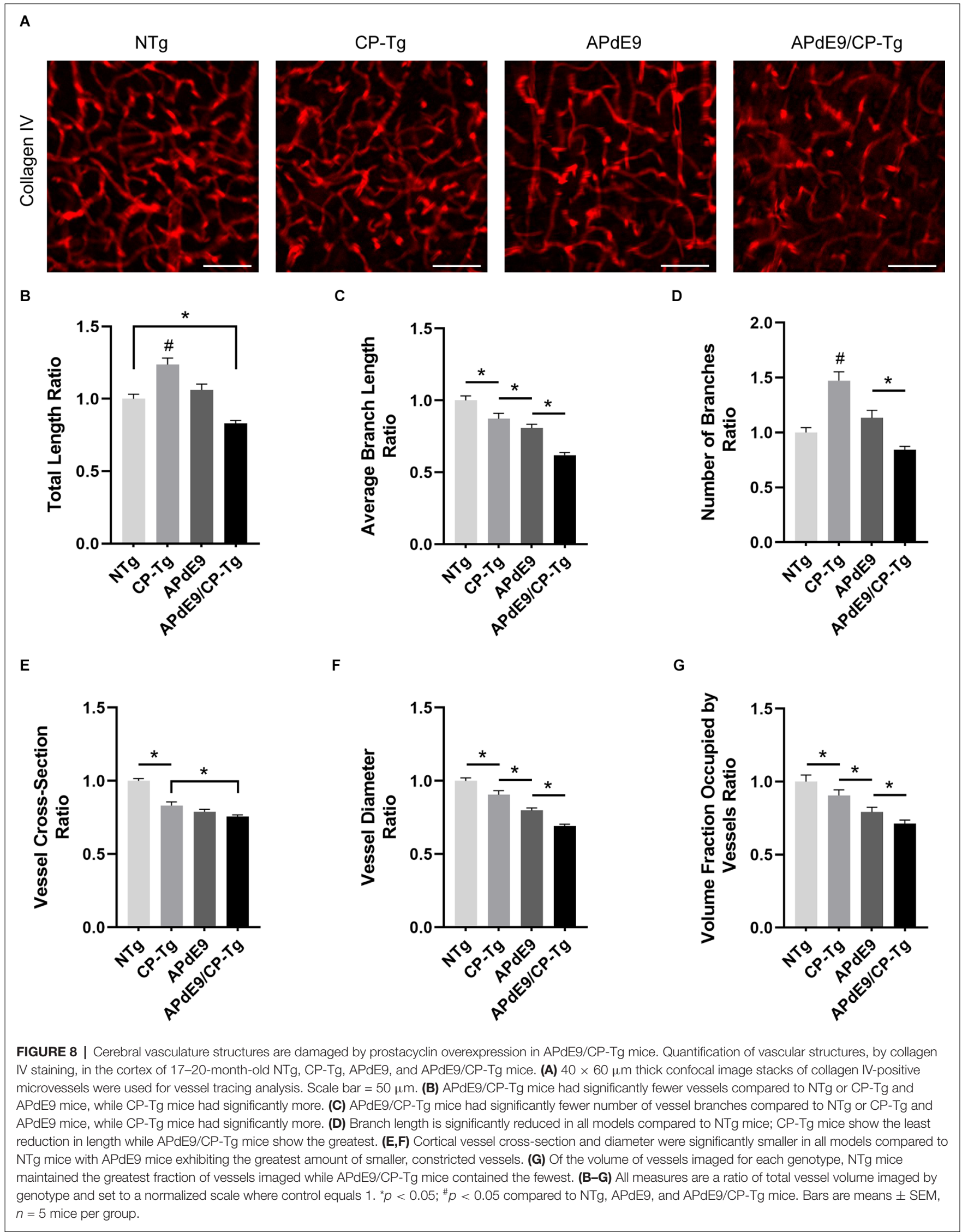



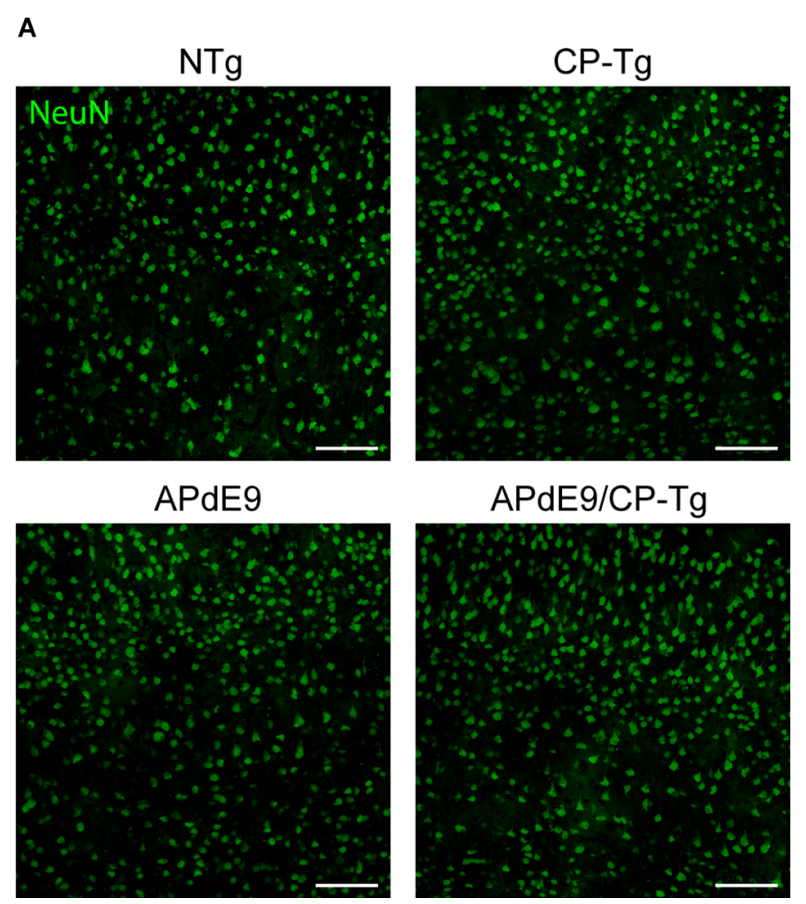

B

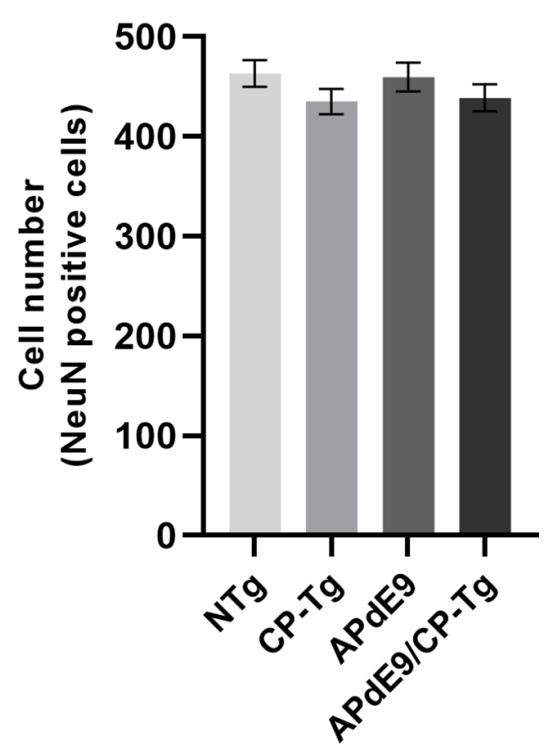

FIGURE 9 | No changes in neuronal loss were detected in cortices of the transgenic mice when compared to the control mice. Quantification of neurons, by NeuN staining, in the cortex of 17-20-month-old NTg, CP-Tg, APdE9, and APdE9/CP-Tg mice. (A) 20x two-dimensional confocal images of NeuN-positive neurons were used for cell counting. Scale bar $=50 \mu \mathrm{m}$. (B) APdE9 mice and both prostacyclin overexpression models showed no loss of cortical neurons. Bars are means \pm SEM, $n=4-5$ mice per group.

cell numbers were detected in the cortex of any genotype when compared to the NTg control mice (Figure 9B).

\section{APdE9/CP-Tg Mice Have an Increased Neuroinflammatory Response}

Ionized calcium-binding adapter molecule 1 (Iba 1) is a factor present in activated microglia during an inflammatory response. Immunostaining with an Ibal antibody in free-floating coronal brain slices showed significant increases of activated microglia in APdE9/CP-Tg mice in comparison with $\mathrm{NTg}$ mice (Figures 10A,B, $p<0.05$ ). Manual quantification in ImageJ showed a 4-fold increase in Iba 1-positive cell counts in APdE9/CP-Tg mice compared to NTg mice. APdE9 mice exhibited an upward trend in activated microglia; however, this effect was not found to be significant (Figure 10B, $p=0.09$ ).

\section{DISCUSSION}

In this study, we characterized the effect of upregulated $\mathrm{PGI}_{2}$ production on behavior, $A \beta$ pathology, and vessel morphology in a mouse model of $\mathrm{AD}$. Previous work has implicated that exogenous application of $\mathrm{PGI}_{2}$ recovers neurological activity in animal models of ischemia or stroke, improves cerebral blood flow, and prevents pericyte loss and vascular leakage after lipopolysaccharide-induced spinal cord injury in mice (Dogan et al., 1996; Matsuda et al., 1997; Muramatsu et al., 2015; Yang et al., 2017).
We first addressed the possible neuroprotective effects of $\mathrm{PGI}_{2}$ overexpression on cognitive and non-cognitive behaviors. In an open field assessment of locomotor activity, both $\mathrm{A} \beta$-expressing lines (APdE9 and APdE9/CP-Tg), displayed hyperactivity when compared to the $\mathrm{CP}-\mathrm{Tg}$ or $\mathrm{NTg}$ controls at 12 months of age. CP-Tg mice exhibited decreased activity and spent a larger amount of time along the margin of the field, similar to findings from our previous work (Vollert et al., 2014). $\mathrm{PGI}_{2}$ overexpression, alone and with the APdE9 phenotype, significantly improved coordination by the last two rotarod trials; we speculate that improvements in motor coordination may be due to increased IP receptor signal in regions involved in motor learning (i.e., striatopallidal and cerebellum) as elevated cAMP is associated with improved motor function (Augustin et al., 2014). Elevated plus-maze and light-dark tests were used to assess anxiety-like behavior. Both measures of anxiety-like behavior revealed increased anxiety in all transgenic models (CP-Tg, APdE9, and APdE9/CP-Tg) measured by time spent in the lit compartment and open arms. Previous reports of the APdE9 mouse model observed similar results as the APPswe/PS1dE9 mice displayed increased exploration in an open field and open arms of an elevated plus-maze (Lalonde et al., 2005). Notably, $\mathrm{PGI}_{2}$ overexpression did not affect anxiety-like behavior in the APdE9 model as the APdE9/CP-Tg mice performed similarly to APdE9 mice. However, $\mathrm{PGI}_{2}$ overexpression was enough to produce an anxiety phenotype. 


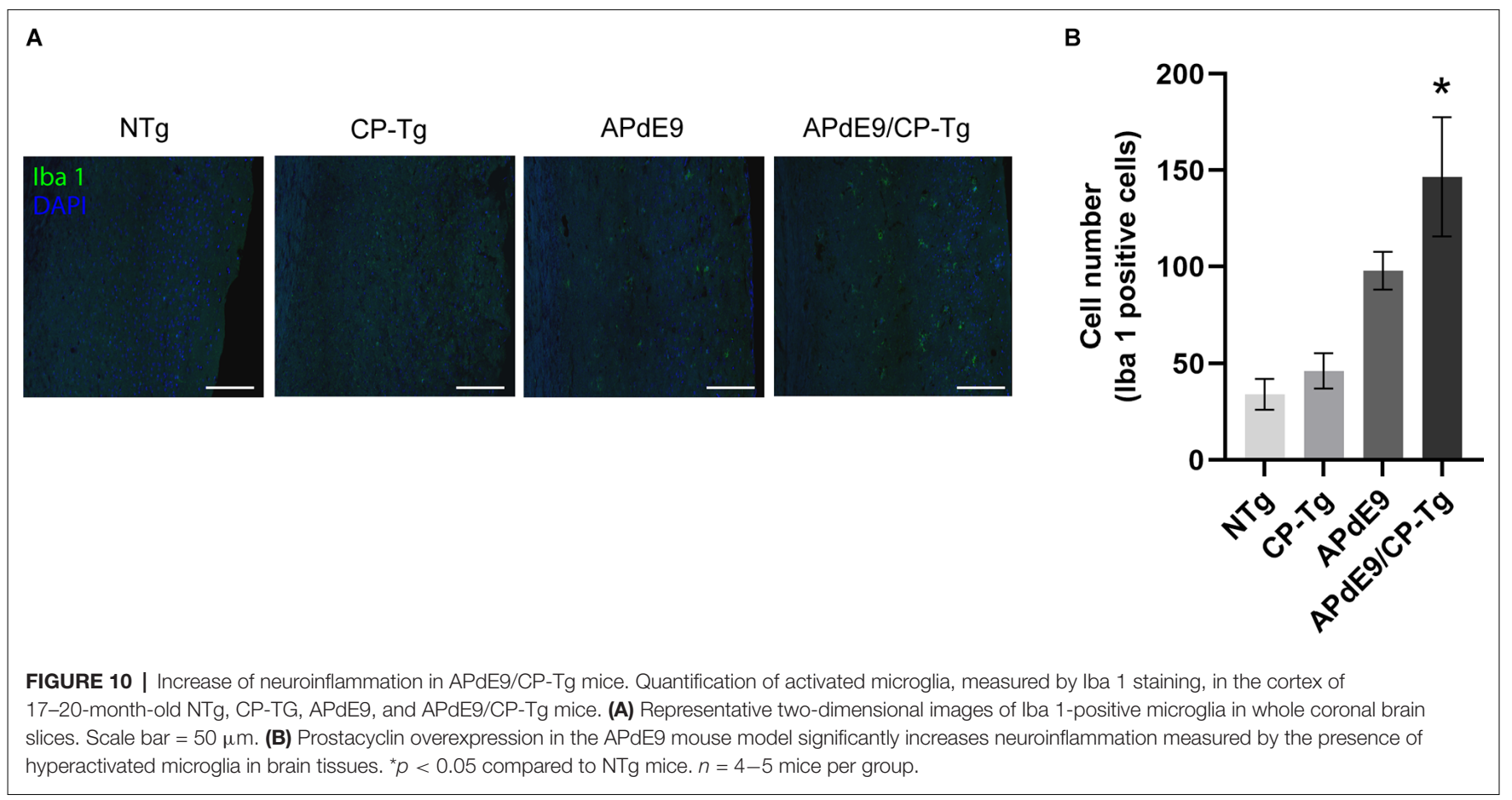

Recent work has suggested that activation of the IP receptor, a cyclic adenosine monophosphate (cAMP)-dependent PKA pathway, may be sufficient to drive stress responses in vivo (Keil et al., 2016). Stimulation of this pathway leads to activation of cAMP-responsive elements binding proteins in the nucleus to synthesize new proteins that alter fear learning and memory formation (Keil et al., 2016). Increased expression of prostacyclin also appeared to exert detrimental effects on other cognitive tests. We observed impaired learning in APdE9/CP-Tg mice during an associative fear conditioning test. Mice were conditioned to a cue and then assessed for contextual and cued memory to the environment or a tone, respectively. During training, APdE9/CP$\mathrm{Tg}$ mice exhibited a significantly reduced freezing response compared to controls indicating a delay in memory acquisition. Additionally, CP-Tg mice also showed delayed acquisition when compared to non-transgenic controls at the third and fifth minutes following the 2-min and 4-min tone-shock pairings. A hippocampal-dependent contextual test was performed $1 \mathrm{~h}$ and $24 \mathrm{~h}$ after training. APdE9/CP-Tg mice again showed reduced freezing response compared to all controls at $1 \mathrm{~h}$, and $24 \mathrm{~h}$ were comparable with $\mathrm{CP}-\mathrm{Tg}$ and non-transgenic controls.

Conversely, previous studies using an exogenous application of a prostacyclin analog, MRE-269, after stroke in aged rats, were able to recover long-term locomotor and somatosensory functions (Yang et al., 2017). Although IP receptor deletion in mice can be neuroprotective with acute insults such as ischemic damage (Wei et al., 2008), chronic $\mathrm{PGI}_{2}$ overexpression may exert adverse effects. Our work demonstrates that elevated levels of prostacyclin impair hippocampal memory function in the presence of $A \beta$ insults. Fear behavior during a 24-h auditory cue test was comparable between all groups. As cued conditioning is hippocampal-independent as it requires the use of the amygdala, our results indicate the combination of $\mathrm{A} \beta$, and prostacyclin expression has little to no effect on amygdala-mediated memory retention.

We also find that $\mathrm{PGI}_{2}$ overexpression significantly increases $\mathrm{A} \beta$ production in APdE9/CP-Tg mice. APdE9 mice begin to develop plaques around 6 months of age, with abundant plaques around 12 months of age, and show behavioral impairments in spatial learning by 12 months of age (Jankowsky et al., 2004). In this study, ELIZAs of whole-brain homogenates show a more than 1.5-fold increase in insoluble $\mathrm{A} \beta 40$ and $\mathrm{A} \beta 42$ in the double transgenic line compared to the APdE9 mice suggesting $\mathrm{A} \beta$ burden is directly affected by prostacyclin expression. Intriguingly, these increases are associated with a selective increase of $A \beta 42$ in the soluble pool, suggesting that prostacyclin may selectively bias $\gamma$-secretase processing. Another interesting observation in this study was the finding that prostacyclin caused an average $40 \%$ increase in plaque diameter, but without a detectible increase in the overall number, perhaps suggesting that factors involved in $A \beta$ metabolism may be modulated through the IP receptor. These findings are supported by recent work on prostacyclin signaling influencing APP processing mechanisms. Agonist activation of the IP receptor was found to increase the expression of the $\mathrm{A} \beta \mathrm{PP}$, resulting in the increased production of $A \beta$ (He et al., 2017). Another report suggests that downstream activation of the PKA/CREB pathway after prostacyclin injections induces upregulation of $\gamma$-secretase cleaving enzymes and leads to an accumulation of $\mathrm{A} \beta \mathrm{c}$-terminal fragments in an APP/PS1 transgenic mouse model (Wang et al., 2016).

Substantial evidence has shown that disruptions to the neurovasculature are evident in humans and mouse models of 
Alzheimer's disease (AD) that directly coincide with an earlier onset and accelerated progression of $\mathrm{AD}$-related pathologies (Bell and Zlokovic, 2009; Zlokovic, 2011; Snyder et al., 2015). These disruptions include altered cerebrovascular functions such as reduced cerebral blood flow velocities and higher resistance indexes (Jin et al., 2017) that have been correlated with impaired cognition (Roher et al., 2012; Ezzati et al., 2017). Structural abnormalities include changes such as capillary atrophy, cell degeneration, loss of tight junction proteins within the bloodbrain barrier, and basement membrane thickening due to cerebral amyloid angiopathy (CAA) in both mouse models and individuals with AD (Thal et al., 2008; Bell, 2012; Kelleher and Soiza, 2013; Sengillo et al., 2013; Lai et al., 2015). However, a complete description of how vascular pathology can affect $\mathrm{AD}$ progression, and the role of the inflammatory pathway in vascular and neuronal injuries, is still being investigated.

Using a volumetric analysis, we measured the impact of $\mathrm{PGI}_{2}$ overexpression on vascular structure within the brain, quantifying measures of vessels such as length, branching, diameter, and volume. Our results show that the combination of $\mathrm{PGI}_{2}$ overexpression with the $\mathrm{A} \beta$ phenotype was quite detrimental and worsened multiple measures of vascular structure. Compared with the control group, APdE9/CP-Tg mice had fewer vessels with shorter, smaller diameters. Compared to NTg mice, APdE9 mice had significantly smaller branch lengths, cross-sections, and diameters, as well as a reduction in total volume. Reductions in microvascular density and vessel constriction have been reported in individuals with $\mathrm{AD}$ and mouse models of $\mathrm{AD}$. Other studies have suggested that $\mathrm{A} \beta$ insults can increase microvascular density in mice (Biron et al., 2013), and there is evidence of angiogenic vessels, accompanied by higher microvessel density, in the hippocampus of post-mortem tissues of individuals diagnosed with AD (Desai et al., 2009). Moreover, some studies have found no changes in vessel volume in both humans and APP/PS1 mice (Hooijmans et al., 2007; Hunter et al., 2012; Burke et al., 2014). In our studies, we also found an increase in total vessel length and degree of branching in the $\mathrm{CP}-\mathrm{Tg}$ mice compared to their non-transgenic controls or both $\mathrm{A} \beta$ models. However, the CP-Tg mice exhibited significantly smaller diameters and cross-sections and had a lower volume than that of NTg mice, indicating that the overproduction of $\mathrm{PGI}_{2}$ is detrimental to the neurovasculature.

The regulatory function of the IP receptor in the vasculature of the brain is poorly understood. Consequently, alterations in vasculature led us to examine perivascular cells or pericytes of the $\mathrm{BBB}$. These cells maintain the integrity of the cerebral vasculature by promoting tight junction protein expression, facilitate cellto-cell alignment, and are integral to preventing leakage of neurotoxic macromolecules that lead to neuronal damage (Bell et al., 2010). Application of $\mathrm{PGI}_{2}$ after lipopolysaccharideinduced vascular damage in a mouse model of spinal cord injury was able to rescue pericyte loss and concurrent leakage of blood components into the central nervous system (Muramatsu et al., 2015). Previous work has reported that accumulation of $\mathrm{A} \beta$ in the neurovasculature of $\mathrm{AD}$ individuals was correlated with reduced coverage of pericytes on capillaries in $\mathrm{AD}$ brains compared to controls (Sengillo et al., 2013). Furthermore, studies of pericyte-deficient, $\mathrm{APP}^{s w / 0}$ (Swedish mutation) mice showed that they had accelerated levels of $A \beta$ deposition, increased tau pathology, and increased neuronal degeneration by 9 months of age when compared to AD control mice (Sagare et al., 2013). In our studies, we evaluated the percentage of CD-13-positive pericytes that co-located with the vessels' basement membrane as a measure of coverage. CP-Tg mice exhibited a significant reduction in pericyte coverage compared to non-transgenic controls, demonstrating that $\mathrm{PGI}_{2}$ plays a modulatory role in pericyte function. We identified significant reductions in pericyte coverage of APdE9 and APdE9/CP-Tg mice compared to NTg and CP-Tg mice. However, no difference was observed between APdE9 and APdE9/CP-Tg mice, indicating that A $\beta$ dependent reductions in pericyte coverage are unaffected by prostacyclin overproduction.

We conclude that $\mathrm{PGI}_{2}$ expression worsened multiple measures associated with degenerative pathology. We observed that $\mathrm{PGI}_{2}$ overexpression influences anxiety, possibly due to increases in cAMP activity that has been reported to alter gene expression of proteins involved with the fear response. APdE9 and APdE9/CP-Tg mice exhibited the same level of anxiety as the CP-Tg mice in the light-dark and elevated-plus maze behavioral tests suggesting $\mathrm{PGI}_{2}$ does not increase the anxiety effect observed in the $\mathrm{AD}$ model. In a fear conditioning test, the APdE9/CP-Tg mice exhibited significantly worse associative memory acquisition and consolidation than APdE9 controls. Although earlier reports using $\mathrm{PGI}_{2}$ analogs suggest activation of the IP receptor could be neuroprotective, $\mathrm{CP}-\mathrm{Tg}$ mice presented with memory deficits when compared to non-transgenic controls; degenerative pathology was not associated with neuronal loss. In our studies, increased production of $\mathrm{PGI}_{2}$ accelerated amyloidogenesis by more than $50 \%$, significantly increasing the production of soluble and insoluble $A \beta$ peptides. Overexpression of $\mathrm{PGI}_{2}$ severely impacted multiple measures of vascular health, a process that was exacerbated with $A \beta$ pathology. Given that prostacyclin is largely protective when expressed in peripheral tissues, our observations suggest that IP signaling is fundamentally different in the cerebrovasculature. Neuroinflammation was also synergistically elevated in the double transgenic model that was not seen with prostacyclin or amyloid overexpression alone. This suggests an immunomodulatory role for prostacyclin signaling in AD. Future studies should explore the mechanism of $\mathrm{PGI}_{2}$ signaling through its respective receptor within specific cell types of the CNS to better understand the role $\mathrm{PGI}_{2}$ plays in influencing the progression of neurodegenerative disease.

\section{DATA AVAILABILITY STATEMENT}

The raw data supporting the conclusions of this article will be made available by the authors, without undue reservation.

\section{ETHICS STATEMENT}

The animal study was reviewed and approved by Institutional Animal Care and Use Committee, University of Houston. 


\section{AUTHOR CONTRIBUTIONS}

TW, OO-N, MM, DM, and JE designed research. TW, OO-N, $\mathrm{CV}, \mathrm{SM}, \mathrm{MS}$, and TB performed research. TW, CV, OO-N, TB, and JE analyzed data. TW and JE wrote the article. All authors contributed to the article and approved the submitted version.

\section{FUNDING}

Research reported in this publication was supported by intramural funding from the University of Houston (JE), the

\section{REFERENCES}

Augustin, S. M., Beeler, J. A., McGehee, D. S., and Zhuang, X. (2014). Cyclic AMP and afferent activity govern bidirectional synaptic plasticity in striatopallidal neurons. J. Neurosci. 34, 6692-6699. doi: 10.1523/JNEUROSCI.3906-13. 2014

Bell, R. D. (2012). The imbalance of vascular molecules in Alzheimer's disease. J. Alzheimers Dis. 32, 699-709. doi: 10.3233/JAD-2012-121060

Bell, R. D., Winkler, E. A., Sagare, A. P., Singh, I., LaRue, B., Deane, R., et al. (2010). Pericytes control key neurovascular functions and neuronal phenotype in the adult brain and during brain aging. Neuron 68, 409-427. doi: 10.1016/j.neuron. 2010.09.043

Bell, R. D., and Zlokovic, B. V. (2009). Neurovascular mechanisms and bloodbrain barrier disorder in Alzheimer's disease. Acta Neuropathol. 118, 103-113. doi: 10.1007/s00401-009-0522-3

Biron, K. E., Dickstein, D. L., Gopaul, R., Fenninger, F., and Jefferies, W. A. (2013). Cessation of neoangiogenesis in Alzheimer's disease follows amyloid-beta immunization. Sci. Rep. 3:1354. doi: 10.1038/srep01354

Brüünsgaard, H., and Pedersen, B. K. (2003). Age-related inflammatory cytokines and disease. Immunol. Allergy Clin. North Am. 23, 15-39. doi: 10.1016/s08898561(02)00056-5

Burke, M. J. C., Nelson, L., Slade, J. Y., Oakley, A. E., Khundakar, A. A., and Kalaria, R. N. (2014). Morphometry of the hippocampal microvasculature in post-stroke and age-related dementias. Neuropathol. Appl. Neurobiol. 40, 284-295. doi: 10.1111/nan.12085

Bush, A. I., Martins, R. N., Rumble, B., Moir, R., Fuller, S., Milward, E., et al. (1990). The amyloid precursor protein of Alzheimer's disease is released by human platelets. J. Biol. Chem. 265, 15977-15983.

Casolini, P., Catalani, A., Zuena, A. R., and Angelucci, L. (2002). Inhibition of COX-2 reduces the age-dependent increase of hippocampal inflammatory markers, corticosterone secretion and behavioral impairments in the rat. J. Neurosci. Res. 68, 337-343. doi: 10.1002/jnr. 10192

Cheng, Y., Austin, S. C., Rocca, B., Koller, B. H., Coffman, T. M., Grosser, T., et al. (2002). Role of prostacyclin in the cardiovascular response to thromboxane A2. Science 296, 539-541. doi: 10.1126/science.1068711

Choi, S.-H., and Bosetti, F. (2009). Cyclooxygenase-1 null mice show reduced neuroinflammation in response to $\beta$-Amyloid. Aging (Albany NY) 1, 234-244. doi: 10.18632/aging.100021

Coma, M., Serenó, L., Da Rocha-Souto, B., Scotton, T. C., España, J., Sánchez, M. B., et al. (2010). Triflusal reduces dense-core plaque load, associated axonal alterations and inflammatory changes and rescues cognition in a transgenic mouse model of Alzheimer's disease. Neurobiol. Dis. 38, 482-491. doi: 10.1016/j.nbd.2010.01.019

Cribbs, D. H., Berchtold, N. C., Perreau, V., Coleman, P. D., Rogers, J., Tenner, A. J., et al. (2012). Extensive innate immune gene activation accompanies brain aging, increasing vulnerability to cognitive decline and neurodegeneration: a microarray study. J. Neuroinflammation 9:179. doi: 10.1186/1742-2094-9-179

Desai, B. S., Schneider, J. A., Li, J.-L., Carvey, P. M., and Hendey, B. (2009). Evidence of angiogenic vessels in Alzheimer's disease. J. Neural Transm. (Vienna) 116, 587-597. doi: 10.1007/s00702-009-0226-9
NIA of the National Institutes of Health under award number 1R15AG039008 (JE), and the NHLBI R01HL146745 (DM). The content is solely the responsibility of the authors and does not necessarily represent the official views of the National Institutes of Health.

\section{ACKNOWLEDGMENTS}

The content of this manuscript has been used in the dissertation of the first author, Dr. TW. This manuscript has also appeared online as a preprint in bioRxiv (Womack et al., 2020).

Desbène, C., Malaplate-Armand, C., Youssef, I., Garcia, P., Stenger, C., Sauvée, M., et al. (2012). Critical role of CPLA2 in A $\beta$ oligomer-induced neurodegeneration and memory deficit. Neurobiol. Aging 33, 1123.e17-1123.e29. doi: 10.1016/j. neurobiolaging.2011.11.008

Dogan, A., Temiz, C., Türker, R. K., Egemen, N., and Bas̨kaya, M. K. (1996) Effect of the prostacyclin analogue, iloprost, on infarct size after permanent focal cerebral ischemia. Gen. Pharmacol. 27, 1163-1166. doi: 10.1016/s03063623(96)00051-1

Dunn, K. W., Kamocka, M. M., and McDonald, J. H. (2011). A practical guide to evaluating colocalization in biological microscopy. Am. J. Physiol. Cell Physiol. 300, C723-C742. doi: 10.1152/ajpcell.00462.2010

Edelman, A. B., Jensen, J. T., Doom, C., and Hennebold, J. D. (2013). Impact of the prostaglandin synthase- 2 inhibitor celecoxib on ovulation and luteal events in women. Contraception 87, 352-357. doi: 10.1016/j.contraception.2012. 07.004

Eikelenboom, P., Hack, C. E., Rozemuller, J. M., and Stam, F. C. (1989). Complement activation in Amyloid plaques in Alzheimer's dementia. Virchows Arch. B. Cell Pathol. 56, 259-262. doi: 10.1007/BF02890024

Elhardt, M., Martinez, L., and Tejada-Simon, M. V. (2010). Neurochemical, behavioral and architectural changes after chronic inactivation of NMDA receptors in mice. Neurosci. Lett. 468, 166-171. doi: 10.1016/j.neulet.2009.10. 091

Ezzati, A., Wang, C., Lipton, R. B., Altschul, D., Katz, M. J., Dickson, D. W., et al. (2017). Association between vascular pathology and rate of cognitive decline independent of Alzheimer's disease pathology. J. Am. Geriatr. Soc. 65, 1836-1841. doi: 10.1111/jgs.14903

Fang, Y.-C., Wu, J.-S., Chen, J.-J., Cheung, W.-M., Tseng, P.-H., Tarn, K.-B., et al. (2006). Induction of prostacyclin/PGI2 synthase expression after cerebral ischemia-reperfusion. J. Cereb. Blood Flow Metab. 26, 491-501. doi: 10.1038/sj. jcbfm.9600205

Franklin, K., and Paxinos, G. (2019). Paxinos and Franklin's the Mouse Brain in Stereotaxic Coordinates, Compact - 5th Edition. Amsterdam: Academic Press Available online at: https://www.elsevier.com/books/paxinos-and-franklins -the-mouse-brain-in-stereotaxic-coordinates-compact/franklin/978-0-12 -816159-3. Accessed November 22, 2020.

He, T., Santhanam, A. V. R., Lu, T., d' Uscio, L. V., and Katusic, Z. S. (2017). Role of prostacyclin signaling in endothelial production of soluble Amyloid precursor protein- $\alpha$ in cerebral microvessels. J. Cereb. Blood Flow Metab. 37, 106-122. doi: 10.1177/0271678X15618977

Holcomb, L. A., Gordon, M. N., Jantzen, P., Hsiao, K., Duff, K., and Morgan, D. (1999). Behavioral changes in transgenic mice expressing both Amyloid precursor protein and presenilin-1 mutations: lack of association with amyloid deposits. Behav. Genet. 29, 177-185. doi: 10.1023/a:1021691918517

Holcomb, L., Gordon, M. N., McGowan, E., Yu, X., Benkovic, S., Jantzen, P., et al. (1998). Accelerated Alzheimer-type phenotype in transgenic mice carrying both mutant amyloid precursor protein and presenilin 1 transgenes. Nat. Med. 4, 97-100. doi: 10.1038/nm0198-097

Holmes, C., Cunningham, C., Zotova, E., Woolford, J., Dean, C., Kerr, S., et al. (2009). Systemic inflammation and disease progression in Alzheimer disease. Neurology 73, 768-774. doi: 10.1212/WNL.0b013e3181b6bb95

Hooijmans, C. R., Graven, C., Dederen, P. J., Tanila, H., Groen, T. v., and Kiliaan, A. J. (2007). Amyloid beta deposition is related to decreased glucose 
transporter-1 levels and hippocampal atrophy in brains of aged APP/PS1 mice. Brain Res. 1181, 93-103. doi: 10.1016/j.brainres.2007.08.063

Hoozemans, J. J. M., Rozemuller, J. M., Haastert, E. S. v., Veerhuis, R., and Eikelenboom, P. (2008). Cyclooxygenase-1 and -2 in the different stages of Alzheimer's disease pathology. Curr. Pharm. Des. 14, 1419-1427. doi: $10.2174 / 138161208784480171$

Hoozemans, J. J., Rozemuller, A. J., Janssen, I., De Groot, C. J., Veerhuis, R., and Eikelenboom, P. (2001). Cyclooxygenase expression in microglia and neurons in Alzheimer's disease and control brain. Acta Neuropathol. 101, 2-8. doi: $10.1007 / \mathrm{s} 004010000251$

Hoshino, T., Namba, T., Takehara, M., Nakaya, T., Sugimoto, Y., Araki, W., et al. (2009). Prostaglandin E2 stimulates the production of Amyloid-beta peptides through internalization of the EP4 receptor. J. Biol. Chem. 284, 18493-18502. doi: 10.1074/jbc.M109.003269

Hunter, J. M., Kwan, J., Malek-Ahmadi, M., Maarouf, C. L., Kokjohn, T. A., Belden, C., et al. (2012). Morphological and pathological evolution of the brain microcirculation in aging and Alzheimer's disease. PLoS One 7:e36893. doi: 10.1371 /journal.pone. 0036893

Itagaki, S., McGeer, P. L., and Akiyama, H. (1988). Presence of T-cytotoxic suppressor and leucocyte common antigen positive cells in Alzheimer's disease brain tissue. Neurosci. Lett. 91, 259-264. doi: 10.1016/0304-3940(88)90690-8

Jankowsky, J. L., Fadale, D. J., Anderson, J., Xu, G. M., Gonzales, V., Jenkins, N. A., et al. (2004). Mutant presenilins specifically elevate the levels of the 42 residue beta-amyloid peptide in vivo: evidence for augmentation of a 42 -Specific gamma secretase. Hum. Mol. Genet. 13, 159-170. doi: 10.1093/hmg/ddh019

Jin, W.-S., Bu, X.-L., Wang, Y.-R., Li, L., Li, W.-W., Liu, Y.-H., et al. (2017). Reduced cardiovascular functions in patients with Alzheimer's disease. J. Alzheimers Dis. 58, 919-925. doi: 10.3233/JAD-170088

Keene, C. D., Chang, R. C., Lopez-Yglesias, A. H., Shalloway, B. R., Sokal, I., Li, X., et al. (2010). Suppressed accumulation of cerebral amyloid $\beta$ peptides in aged transgenic Alzheimer's disease mice by transplantation with wild-type or prostaglandin E2 receptor subtype 2-Null bone marrow. Am. J. Pathol. 177, 346-354. doi: 10.2353/ajpath.2010.090840

Keil, M. F., Briassoulis, G., and Stratakis, C. A. (2016). The role of protein kinase A in anxiety behaviors. Neuroendocrinology 103, 625-639. doi: $10.1159 / 000444880$

Kelleher, R. J., and Soiza, R. L. (2013). Evidence of endothelial dysfunction in the development of Alzheimer's disease: is Alzheimer's a vascular disorder? Am. J. Cardiovasc. Dis. 3, 197-226.

Kitamura, Y., Shimohama, S., Koike, H., Kakimura, J. i, Matsuoka, Y., Nomura, Y., et al. (1999). Increased expression of cyclooxygenases and peroxisome proliferator-activated receptor-gamma in Alzheimer's disease brains. Biochem. Biophys. Res. Commun. 254, 582-586. doi: 10.1006/bbrc.1998.9981

Lai, A. Y., Dorr, A., Thomason, L. A. M., Koletar, M. M., Sled, J. G., Stefanovic, B., et al. (2015). Venular degeneration leads to vascular dysfunction in a transgenic model of Alzheimer's disease. Brain 138, 1046-1058. doi: 10.1093/brain/awv023

Lalonde, R., Kim, H. D., Maxwell, J. A., and Fukuchi, K. (2005). Exploratory activity and spatial learning in 12-month-old APP(695)SWE/Co+PS1/DeltaE9 mice with amyloid plaques. Neurosci. Lett. 390, 87-92. doi: 10.1016/j.neulet.2005.08.028

Liang, X., Wang, Q., Hand, T., Wu, L., Breyer, R. M., Montine, T. J., et al. (2005a). Deletion of the prostaglandin E2 EP2 receptor reduces oxidative damage and amyloid burden in a model of Alzheimer's disease. J. Neurosci. 25, 10180-10187. doi: 10.1523/JNEUROSCI.3591-05.2005

Liang, X., Wu, L., Hand, T., and Andreasson, K. (2005b). Prostaglandin D2 mediates neuronal protection via the DP1 receptor. J. Neurochem. 92, 477-486. doi: 10.1111/j.1471-4159.2004.02870.x

Ling, Q.-L., Mohite, A. J., Murdoch, E., Akasaka, H., Li, Q.-Y., So, S.-P., et al. (2018). Creating a mouse model resistant to induced ischemic stroke and cardiovascular damage. Sci. Rep. 8:1653. doi: 10.1038/s41598-018-19661-y

Liu, B., Zhang, Y., Zhu, N., Li, H., Luo, W., and Zhou, Y. (2013). A vasoconstrictor role for cyclooxygenase-1-mediated prostacyclin synthesis in mouse renal arteries. Am. J. Physiol. Renal Physiol. 305, F1315-1322. doi: 10.1152/ajprenal. 00332.2013

Martinez, L. A., Klann, E., and Tejada-Simon, M. V. (2007). Translocation and activation of Rac in the hippocampus during associative contextual fear learning. Neurobiol. Learn. Mem. 88, 104-113. doi: 10.1016/j.nlm.2007.01.008
Matsuoka, T., Hirata, M., Tanaka, H., Takahashi, Y., Murata, T., Kabashima, K., et al. (2000). Prostaglandin D2 as a mediator of allergic asthma. Science 287, 2013-2017. doi: 10.1126/science.287.5460.2013

Matsuda, S., Wen, T.-C., Karasawa, Y., Araki, H., Otsuka, H., Ishihara, K., et al. (1997). Protective effect of a prostaglandin I2 analog, TEI-7165, on ischemic neuronal damage in gerbils. Brain Res. 769, 321-328. doi: 10.1016/s00068993(97)00724-5

McGeer, P. L., Itagaki, S., Boyes, B. E., and McGeer, E. G. (1988). Reactive microglia are positive for HLA-DR in the substantia nigra of Parkinson's and Alzheimer's disease brains. Neurology 38, 1285-1291. doi: 10.1212/wnl.38.8. 1285

Muramatsu, R., Kuroda, M., Matoba, K., Lin, H., Takahashi, C., Koyama, Y., et al. (2015). Prostacyclin prevents pericyte loss and demyelination induced by lysophosphatidylcholine in the central nervous system. J. Biol. Chem. 290, 11515-11525. doi: 10.1074/jbc.M114.587253

Noble, J. M., Manly, J. J., Schupf, N., Tang, M. X., Mayeux, R., and Luchsinger, J. A. (2010). Association of C-reactive protein to cognitive impairment. Arch. Neurol. 67, 87-92. doi: 10.1001/archneurol.2009.308

Oida, H., Namba, T., Sugimoto, Y., Ushikubi, F., Ohishi, H., Ichikawa, A., et al. (1995). In situ hybridization studies of prostacyclin receptor MRNA expression in various mouse organs. Br. J. Pharmacol. 116, 2828-2837. doi: 10.1111/j.14765381.1995.tb15933.x

Ricciotti, E., and FitzGerald, G. A. (2011). Prostaglandins and inflammation. Arterioscler. Thromb. Vasc. Biol. 31, 986-1000. doi: 10.1161/ATVBAHA.110. 207449

Rogers, J., Luber-Narod, J., Styren, S. D., and Civin, W. H. (1988). Expression of immune system-associated antigens by cells of the human central nervous system: relationship to the pathology of Alzheimer's disease. Neurobiol. Aging 9, 339-349. doi: 10.1016/s0197-4580(88)80079-4

Roher, A. E., Debbins, J. P., Malek-Ahmadi, M., Chen, K., Pipe, J. G., Maze, S., et al. (2012). Cerebral blood flow in Alzheimer's disease. Vasc. Health Risk Manag. 8, 599-611. doi: 10.2147/VHRM.S34874

Ruan, K.-H., Deng, H., and So, S.-P. (2006). Engineering of a protein with cyclooxygenase and prostacyclin synthase activities that converts arachidonic acid to prostacyclin. Biochemistry 45, 14003-14011. doi: 10.1021/ bi0614277

Ruan, K.-H., Jiaxin, W., and Cervantes, V. (2008). Characterization of the substrate mimic bound to engineered prostacyclin synthase in solution using high-resolution NMR spectroscopy and mutagenesis: implication of the molecular mechanism in biosynthesis of prostacyclin. Biochemistry 47, 680-688. doi: 10.1021/bi701671q

Sagare, A. P., Bell, R. D., Zhao, Z., Ma, Q., Winkler, E. A., Ramanathan, A., et al. (2013). Pericyte loss influences Alzheimer-like neurodegeneration in mice. Nat. Commun. 4:2932. doi: 10.1038/ncomms3932

Sagy-Bross, C., Hadad, N., and Levy, R. (2013). Cytosolic phospholipase A2 $\alpha$ upregulation mediates apoptotic neuronal death induced by aggregated amyloid- $\beta$ peptide1-42. Neurochem. Int. 63, 541-550. doi: 10.1016/j.neuint. 2013.09.007

Sengillo, J. D., Winkler, E. A., Walker, C. T., Sullivan, J. S., Johnson, M., and Zlokovic, B. V. (2013). Deficiency in mural vascular cells coincides with bloodbrain barrier disruption in Alzheimer's disease. Brain Pathol. 23, 303-310. doi: 10.1111/bpa.12004

Shi, J., Wang, Q., Johansson, J. U., Liang, X., Woodling, N. S., Priyam, P., et al. (2012). Inflammatory prostaglandin E2 signaling in a mouse model of Alzheimer disease. Ann. Neurol. 72, 788-798. doi: 10.1002/ana. 23677

Siegle, I., Klein, T., Zou, M. H., Fritz, P., and Kömhoff, M. (2000). Distribution and cellular localization of prostacyclin synthase in human brain. J. Histochem. Cytochem. 48, 631-641. doi: 10.1177/002215540004800507

Simen, A. A., Bordner, K. A., Martin, M. P., Moy, L. A., and Barry, L. C. (2011). Cognitive dysfunction with aging and the role of inflammation. Ther. Adv. Chronic Dis. 2, 175-195. doi: 10.1177/2040622311399145

Smith, C. C. T., Stanyer, L., and Betteridge, D. J. (2004). Soluble $\beta$ amyloid $(\mathrm{A} \beta) 40$ causes attenuation or potentiation of noradrenaline-induced vasoconstriction in rats depending upon the concentration employed. Neurosci. Lett. 367, 129-132. doi: 10.1016/j.neulet.2004.05.094

Snyder, H. M., Corriveau, R. A., Craft, S., Faber, J. E., Greenberg, S. M., Knopman, D., et al. (2015). Vascular contributions to cognitive impairment 
and dementia including Alzheimer's disease. Alzheimers Dement. 11, 710-717. doi: 10.1016/j.jalz.2014.10.008

Starr, M. E., Evers, B. M., and Saito, H. (2009). Age-associated increase in cytokine production during systemic inflammation: adipose tissue as a major source of IL-6. J. Gerontol. A. Biol. Sci. Med. Sci. 64, 723-730. doi: 10.1093/gerona/glp046

Thal, D. R., Griffin, W. S. T., Vos, R. A. I. de., and Ghebremedhin, E. (2008). Cerebral amyloid angiopathy and its relationship to Alzheimer's disease. Acta Neuropathol. 115, 599-609. doi: 10.1007/s00401-008-0366-2

Tischer, C., and Tosi, S. (2016). "Tumor blood vessels: 3d tubular network analysis," in Bioimage Data Analysis ed K. Miura (Weinheim, Germany: WileyVCH), 219-236.

Vitale, P., Tacconelli, S., Perrone, M. G., Malerba, P., Simone, L., Scilimati, A., et al. (2013). Synthesis, pharmacological characterization and docking analysis of a novel family of diarylisoxazoles as highly selective cyclooxygenase-1 (COX-1) inhibitors. J. Med. Chem. 56, 4277-4299. doi: 10.1021/jm301905a

Vollert, C., Ohia, O., Akasaka, H., Berridge, C., Ruan, K.-H., and Eriksen, J. L. (2014). Elevated prostacyclin biosynthesis in mice impacts memory and anxiety-like behavior. Behav. Brain Res. 258, 138-144. doi: 10.1016/j.bbr.2013. 10.012

Wang, P., Guan, P.-P., Guo, J.-W., Cao, L.-L., Xu, G.-B., Yu, X., et al. (2016). Prostaglandin $\mathrm{I} 2$ upregulates the expression of anterior pharynx-defective$1 \alpha$ and anterior pharynx-defective- $1 \beta$ in amyloid precursor protein/presenilin 1 transgenic mice. Aging Cell 15, 861-871. doi: 10.1111/acel.12495

Wei, G., Kibler, K. K., Koehler, R. C., Maruyama, T., Narumiya, S., and Doré, S. (2008). Prostacyclin receptor deletion aggravates hippocampal neuronal loss after bilateral common carotid artery occlusion in mouse. Neuroscience 156, 1111-1117. doi: 10.1016/j.neuroscience.2008.07.073

Womack, T. R., Vollert, C., Nwoko, O., Schmitt, M., Montazari, S., Beckett, T., et al. (2020). Prostacyclin promotes degenerative pathology in a model of Alzheimer's disease. bioRxiv [Preprint]. doi: 10.1101/2020.04.15.039842

Yang, C., DeMars, K. M., Alexander, J. C., Febo, M., and Candelario-Jalil, E. (2017). Sustained neurological recovery after stroke in aged rats treated with a novel prostacyclin analog. Stroke 48, 1948-1956. doi: 10.1161/STROKEAHA. 117.016474

Yermakova, A. V., Rollins, J., Callahan, L. M., Rogers, J., and O’Banion, M. K. (1999). Cyclooxygenase-1 in human Alzheimer and control brain: quantitative analysis of expression by microglia and CA3 hippocampal neurons. J. Neuropathol. Exp. Neurol. 58, 1135-1146. doi: 10.1097/00005072-19991100000003

Zhen, G., Kim, Y. T., Li, R., Yocum, J., Kapoor, N., Langer, J., et al. (2012). PGE2 EP1 receptor exacerbated neurotoxicity in a mouse model of cerebral ischemia and Alzheimer's disease. Neurobiol. Aging 33, 2215-2219. doi: 10.1016/j.neurobiolaging.2011.09.017

Zlokovic, B. V. (2011). Neurovascular pathways to neurodegeneration in Alzheimer's disease and other disorders. Nat. Rev. Neurosci. 12, 723-738. doi: $10.1038 / \mathrm{nrn} 3114$

Conflict of Interest: The authors declare that the research was conducted in the absence of any commercial or financial relationships that could be construed as a potential conflict of interest.

Publisher's Note: All claims expressed in this article are solely those of the authors and do not necessarily represent those of their affiliated organizations, or those of the publisher, the editors and the reviewers. Any product that may be evaluated in this article, or claim that may be made by its manufacturer, is not guaranteed or endorsed by the publisher.

Copyright (C) 2022 Womack, Vollert, Ohia-Nwoko, Schmitt, Montazari, Beckett, Mayerich, Murphy and Eriksen. This is an open-access article distributed under the terms of the Creative Commons Attribution License (CC BY). The use, distribution or reproduction in other forums is permitted, provided the original author $(s)$ and the copyright owner(s) are credited and that the original publication in this journal is cited, in accordance with accepted academic practice. No use, distribution or reproduction is permitted which does not comply with these terms. 